The "Crex Crex" Lament: Estimating Landowners

Willingness to Pay for Corncrake Conservation on Irish Farmland

Stephen Hynes

Nick Hanley

Stirling Economics Discussion Paper 2008-14 July 2008

Online at http://www.economics.stir.ac.uk 


\title{
The "Crex crex" Lament: Estimating Landowners Willingness to Pay for Corncrake Conservation on Irish Farmland
}

\author{
Stephen Hynes ${ }^{a *}$, Nick Hanley \\ a. Rural Economy Research Centre (RERC), Teagasc, Ireland \\ b. Department of Economics, \\ University of Stirling, Scotland
}

\begin{abstract}
This paper considers farmers willingness to pay (WTP) to conserve an endangered Irish farmland bird, the Corncrake (Crex crex). An Irish National Farm Survey (NFS) is used to produce individual farm-level WTP estimates for the year 2006. These figures are then aggregated to obtain a total value figure for the farming community of Corncrake conservation in Ireland. We focus on the willingness to pay of farmers rather than the WTP of the general Irish population, as farmers will ultimately be the ones that will have to take responsibility if targets set out in the All Ireland Action Plan for Corncrake conservation are to be achieved. Quantifying willingness to pay on the part of farmers can help inform the design of agri-environment schemes aimed at improving conservation of many bird species on farmland. Results indicate that the non-market benefit of corncrake conservation in Ireland may significantly outweigh the costs of existing conservation schemes.
\end{abstract}

KEYWORDS: contingent valuation, corncrakes, agri-environment schemes, biodiversity. JEL codes: Q51, Q57.

* Corresponding author. Address: Environmental Modelling Unit, Rural Economy Research Centre, Teagasc, Athenry, Galway, Ireland. Tel: +353 (091) 845269, Fax: +353 (091) 844296, E-mail: stephen.hynes@teagasc.ie 


\section{Introduction}

Due to widespread and rapid declines throughout its world range, the International Union for the Conservation of Nature has listed the corncrake as "Near Threatened" (BirdLife International, 2006). In Ireland the corncrake is fully protected, being listed on Schedule 1 of the 1976 Wildlife Act. It is also listed in the Irish Red Data Book of Endangered Species (Whilde, 1993) and on Annex I of the EU Wild Birds Directive. Research on corncrake population declines has suggested that effective conservation measures should include ensuring that sufficient tall vegetation is present in spring and autumn as well as in mid-summer, that the date of mowing be delayed and that using mowing methods that allow chicks to escape be employed (Copland and Donaghy, 2001). Measures have also been included in the Irish Rural Environment Protection Scheme (REPS) to protect the corncrake in the few areas where it can still be found.

The Irish Government introduced the REPS in June 1994 in response to Regulation (EEC) 2078/92. Since its inception, the REPS specifications have been changed on four separate occasions; REPS1 started in 1994, REPS2 in 2000, REPS3 in 2003 and REPS4 in 2007. One of the main objectives of REPS is the protection of wildlife habitats and endangered species of flora and fauna (Department of Agriculture, Food and Rural Development, 1999). The Scheme operates on the assumption that a baseline level of good farming practice is being exceeded, and that additional costs are being incurred in order to farm in a more environment friendly manner. All participants in REPS must carry out their farming activities for a five-year period in line with an agri-environment plan prepared in accordance with the Scheme specifications. The plan is drawn up to be 
specific to each farm and is prepared by a Department of Agriculture approved planning agency (Hynes et al., 2008a).

In all plans, farmers are required to comply with 11 basic measures, plus two additional biodiversity options (from a list of 16 options available) in order to participate in the Scheme. In addition, there are a small number of supplementary measures, from which farmers may choose and, in so doing, receive extra payment. One of the supplementary measures involves specific management prescriptions important for corncrake conservation (delayed or centre-out mowing, and habitat creation measures) on Natural Heritage Areas (statutory sites). This measure known as Corncrake Habitats Supplementary Measure 1 came on stream under the third phase of REPS (REPS3).

To avail of this measure under REPS3, a farmer had to have land within a corncrake habitat area in the Shannon Callows. The farmer also had to participate in a Birdwatch Ireland management plan for corncrake sites. The Shannon Callows takes in portions of five counties, Galway, Tipperary, Offaly, Roscommon, and Westmeath. REPS farmers with land in the Shannon Callows can take up payments of $€ 100$ per hectare in addition to the $€ 242$ per hectare paid on designated land under REPS. The Corncrake Habitats Supplementary Measure was extended under the fourth phase of the scheme (REPS4) which was launched in December 2007. Now farmers in REPS4 can get $€ 100$ additional payment per hectare for any land across Ireland where the corncrake can still be found (Department of Agriculture, Fisheries and Food, 2008a). In 2007, 47 farmers availed of the Corncrake Conservation option under REPS3. 
A Corncrake Grant Scheme, run by the National Parks and Wildlife Service (NPWS) and implemented by BirdWatch Ireland, has also been in operation in the three core areas where the corncrake can still be found today (Co. Donegal, west Connacht and the Shannon Callows) since 1991. The Corncrake Grant Scheme, which is entirely voluntary, offers grants to farmers for delaying mowing and for using "Corncrake-friendly" mowing (mowing from the centre out which allows chicks to escape to safety in headlands and ditches). Anyone who has eligible land close to where a male Corncrake is confirmed calling can participate. Since the scheme started in the West, Corncrake numbers have risen from 19 to 36 calling males. The scheme currently pays $€ 115 /$ hectare to a limited number of farmers who are willing to delay mowing until after 15th August and $€ 150 /$ hectare if mowing is delayed to after 1st September.

In November 2005, the Irish National Parks and Wildlife Service in association with the Department of the Environment, Northern Ireland, published an All Ireland Action Plan for the conservation of the Corncrake (NPWS, 2005). The main targets in this action plan were to:

1. Maintain the existing number and range of corncrakes in Ireland.

2. Maintain corncrake population in the three core areas in the Republic of Ireland where the species can still be found at or above 2003 levels (133 singing males).

3. By 2010 , increase the populations of the three core areas to 150 in Donegal, 50 in West Connacht and 60 in the Shannon Callows.

4. By 2010, establish a population of 7 singing males on Rathlin Island. 
5. By 2015, re-establish breeding populations in other parts of its former range, in suitable areas in both Northern Ireland and the Republic of Ireland.

With these conservation targets in mind this paper considers farmers willingness to pay (WTP) to conserve the Corncrake in Ireland. In particular, the main objective of the paper is to investigate whether the non-market benefits to farmers of corncrake conservation out weight the cost of the conservation schemes currently in place in Ireland for this endangered bird species. A secondary object is to determine if farmers' willingness to pay for the restoration of the corncrake is positively correlated with participation in existing agri-environment schemes and with extensive farm enterprises.

The Irish National Farm Survey (NFS) is used to produce individual farmer-level WTP estimates for the year 2006. These figures are then aggregated to get a total value figure for the farming community of Corncrake conservation in Ireland. Quantifying farmers' WTP is important for two reasons. First, this forms one part of the total social benefits of corncrake conservation in economic terms: adding in the WTP of non-farming local residents, tourists, visitors and people living elsewhere in Ireland would constitute this total non-market benefit from conservation. Second, agri-environment schemes rely on voluntary uptake by farmers for their success (Kleijn and Sutherland, 2003). Most studies of uptake focus on the costs to farmers of undertaking conservation actions on their farms. However, it is possible that an equally important consideration in predicting uptake levels is the value that farmers themselves would enjoy from the achievement of conservation actions. 
In the next section, we briefly discuss current threats to the Corncrake in Ireland. In section 3 we briefly describe the design of our WTP survey and discuss the dataset used. In section 4 the payment card Contingent Valuation methodology and the use of a Generalized Tobit interval modeling approach is reviewed. Model results and WTP estimates are presented in section 5. Finally, section 6 concludes with some recommendations for further research.

\section{The Corncrake in Ireland}

The corncrake is highly secretive bird which is rarely seen in the open, concealing itself effectively in long grass and herbaceous vegetation (Mayes and Stowe, 1989). In Ireland, the corncrake is associated with grass meadows and other areas of dense cover, such as nettle patches. Traditionally, flower-rich hay meadows would have been favored by the birds, and still are in the corncrake's remaining strongholds. Over the last 30 years, corncrakes have suffered from a switch to more intensively managed grassland, which is often destined for cutting as silage too early in the season to allow the birds to breed successfully. Indeed, this is the main reason why the Corncrake is the only Irish breeding bird which is currently threatened with global extinction. It has been listed on the 2006 International Union for the Conservation of Nature (IUCN) Red List of Threatened Species, due to population and range declines of more than $50 \%$ in the last 25 years (BirdLife International, 2006). The history of the corncrake on the IUCN Red List shows that the first time it was listed as threatened was in 1988 (Collar and Andrew, 1988). It was classified as vulnerable in 1994 (Collar et al., 1994) and again as vulnerable in 2000 (BirdLife International 2000). 
There is conclusive evidence to show that declines in corncrake populations are primarily linked to changes in agricultural practice on their breeding grounds (Green and Williams, 1994; Green and Rayment, 1996). Corncrakes began to decline when traditional farming systems began to be replaced by modern agricultural methods. Increasingly sophisticated machinery meant that grass could be cut earlier in the year and more rapidly than ever before. Farmers also began to take several crops of grass per year. Earlier mowing dates have meant that corncrakes and other ground-nesting birds have been prevented from successfully hatching young in the meadows (Bird Watch Ireland, 2000). Research has shown that, in order to maintain population levels, corncrakes need to hatch two broods of chicks per year (Copland and Donaghy, 2001). As the peak hatching date for the second brood is in late July, corncrakes will decline rapidly in areas where most of the mowing takes place before early August (Schäffer and Green, 2001).

Corncrakes were once very common in Ireland. Conservative estimates put the population at the turn of the century in the tens of thousands. By the late 1960s, the population had declined to about 4,000 singing males. The All-Ireland census carried out in 1994 found that the population had dropped to just over 129 singing males (NPWS, 2005). As a result of concentrated conservation measures, however, numbers rose for the first time in 1995. Numbers in 1999 and 2000 showed some stability with around 150 singing males recorded. Numbers have since remained stable and in 2005, the Irish corncrake population stood at 164 . Figure 1 shows where the corncrakes remaining breeding grounds can still be found in Ireland. 
In an effort to examine Irish farmers attitudes to the corncrake, 1,177 nationally representative farmers were asked their willingness to pay (WTP) each year into a conservation fund to aid in the restoration of the corncrake and to bring the singing male population back up to a sustainable population of 900 birds. We take this WTP measure to be indicative of the extent to which farmers will support voluntary agri-environment measures aimed at corncrake conservation.

\section{Data and WTP Survey Questions}

In this section we describe the data used in this paper and the format of the willingness to pay questions. The National Farm Survey (NFS) is collected as part of the Farm Accountancy Data Network of the European Union. The aim of this network is to gather accounting data from farms in all member states of the EU for the determination of incomes and business analysis of agricultural holdings (FADN, 2005). The method of classifying farms into farming systems used in the NFS is based on the EU FADN typology set out in the Commission Decision 78/463. Within the NFS, the farm system variable is broken down into six different categories as follows: Dairying, Dairying and Other, Cattle rearing, Cattle Other, Mainly Sheep and Tillage Systems (NFS, 2003). Table 1 provides summary statistics of a number of key variables in the NFS sample.

In the $2006 \mathrm{NFS}$, the contingent valuation method was employed to estimate the value to the Irish farmer of conserving a rare farmland bird species. The contingent valuation method $(\mathrm{CVM})$ is a survey based stated preference technique which asks respondents 
directly to express their maximum willingness to pay (or willingness to accept) for a hypothetical change to a non-market good (Portney, 1994). CVM is subject to various criticisms regarding its reliability and validity. CVM has however emerged as a valid instrument in estimating the benefits of non-market goods (Mitchell and Carson, 1989; Arrow et al., 1993; Carson, 2000), and has been used before to estimate the benefits of agri-environment programs aimed at bird conservation (MacMillan et al., 2004). CVM was incorporated into the 2006 NFS by asking additional questions in terms of farmers' willingness to pay towards the restoration of the corncrake in the Irish countryside. A pilot sample was used to inform general survey design and to gauge the likely range of farmers' willingness to pay in order to inform the bid design of the main survey.

In carrying out the main survey each interviewee was told about the current population of the corncrake and how its numbers have fallen over the last 20 years. The farmers were also informed that ..."BirdWatch Ireland has operated an intensive Corncrake Conservation Project in Ireland since 1991, with the support of the Department of Environment, Heritage and Local Government and the Royal Society for the Protection of Birds". The farmers were then informed that ..."As the population of corncrakes increases and spreads across the country, their management and maintenance will impose additional costs on the funding bodies, local authorities and local landowners (restrictions in land use) compared to the status quo of no restoration program. This cost would have to be paid for by the general public so it is important to find out how much if anything YOU would be willing to pay to have the corncrake restored as a common sight in the Irish countryside”. 
The farmers interviewed were then asked if they were willing to pay something towards the restoration of the corncrake into the Irish countryside and the maintenance of a sustainable population of corncrakes into the future. The farmers were instructed to bear in mind their total annual budget, the amount they might allocate to wildlife conservation and finally how much of this they could afford to spend on this restoration program. Also, they were told to bear in mind that paying too much for this restoration program may mean that they could not afford other worthwhile wildlife conservation schemes. Respondents answering "No" to this question were then asked which of several statements best described why they were not willing to pay anything. Those who answered the question in the affirmative were then presented with a payment card showing the bid amounts of $€ 10, € 20, € 30, € 40, € 50$ and $€ 60$ and were asked: "of these bid amounts which would be the maximum you would be willing to pay $(€)$ each year into a conservation fund to aid in the restoration of this bird and bring the singing male population back up to a sustainable population of 900 birds".

A total of 1117 surveys were collected. Of these, 42 of these were unusable due to the fact that the recorder did not collect any information on the WTP questions in the NFS. Five more were excluded from the analysis as they indicated that they currently received payment for the conservation of corncrakes from either the NPWS or under the supplementary corncrake measure in REPS. A total of 453 individuals responded that they would be willing to pay something towards a corncrake conservation program. However, 46 of these said they were not willing to pay even the lowest bid value presented to them on the payment card $(€ 10)$. Of the remaining $€ 0 \mathrm{WTP}$ responses, 33 
were treated as protest bids due to the fact that the respondents stated that they were not willing to pay anything because either they felt the payment vehicle was not appropriate or they could not give a legitimate reason why they were WTP $€ 0$. These observations were excluded from the analysis. The total final number of usable responses was 928 .

\section{Methodology}

CVM has been employed extensively to examine the benefits of preserving a wildlife population and habitats (Martin-Lopez et al., 2007; Montgomery et al., 1994; Loomis and White, 1996; Langford et al., 1998; Kroeger et al., 2005). Alternatives within the CVM approach have obviously been debated within this literature. However, as long as the bids are selected with care, and the sample size is not too small, Langford et al. (1998) have pointed out that there is no conclusive evidence that any one alternative is superior to another. The Payment Card Method of CVM (Cameron and Huppert, 1989), as outlined above, was chosen given the data collection method being used. Fifteen separate recorders collect the NFS on the individual farms annually. Given that the farmers are asked over 300 questions in these surveys, it was necessary to choose a simple approach to the WTP questions on the survey to avoid question-answering fatigue on the part of the respondents.

As with any of the response formats in a CVM study, the use of the payment card method has advantages and disadvantages. Advantages are that it can provide a context to the bids and avoids "yea-saying" where some respondents answer yes to any single bid amount presented to them (Blamey et al., 1999). It can also help avoid starting point bias 
and may reduce the number of outliers in the sample (Boyle et al., 1996). The payment card method may also reduce the problem of respondents saying that they would pay high bid amounts that exceed their true values (Boyle et al., 1997). Some of the method's most documented disadvantages are that it can be subject to biases associated with the range of bids used on the card, and that some respondents will choose the first or last number in a sequence. It has also been pointed out that the method may lack incentive compatibility. Boyle (2003, p141) notes that "the literature does not support the choice of a singleresponse format (dichotomous choice) and it does not exclude the use of payment-card and multiple-bounded questions".

The elicitation format of the Payment Card Method involves each farmer being shown a card listing various Euro amounts and being asked to indicate the maximum amount they were willing to pay. Following Cameron and Huppert (1989), the response is interpreted not as an exact statement of willingness to pay but rather as an indication that the WTP lies somewhere between the chosen value and the next larger value above it on the payment card. Table 2 displays the distribution of the usable responses in the farm survey across the intervals. The price range used in this study was based on the responses to a pilot study which utilized the open-ended elicitation format (see Haab and McConnell, 2002).

The WTP responses were treated in a parametric model, where the WTP value chosen by each farmer was specified as: WTP $=\mu+\varepsilon$. It is assumed that $\varepsilon \sim N\left(0, \sigma^{2} I\right)$. This is a generalized Tobit model and is estimated via maximum likelihood procedures. Daniels 
and Rospabé (2005) provide a log-likelihood function adjusted to make provision for point, left-censored, right-censored (top WTP category with only a lower bound) and interval data. For farmers $j \in C$, we observe $W T P_{j}$, i.e. point data and for farmers $j \in L$, $W T P_{j}$ are left censored. Farmers $j \in R$ are right censored; we know only that the unobserved $W T P_{j}$ is greater than or equal to $W T P_{R j}$. Finally farmers $j \in I$ are intervals; we know only that the unobserved $W T P_{j}$ is in the interval $\left[W T P_{1 j}, W T P_{2 j}\right]$. The $\log$ likelihood is then given by:

$$
\begin{aligned}
& \ln L=-\frac{1}{2} \sum_{j \in C} w_{j}\left\{\left(\frac{W T P_{j}-x \beta}{\sigma}\right)+\log 2 \pi \sigma^{2}\right\}+\sum_{j \in L} w_{j} \log \Phi\left\{\left(\frac{W T P_{L j}-x \beta}{\sigma}\right)\right\} \\
& +\sum_{j \in R} w_{j} \log \left\{1-\Phi\left(\frac{W T P_{R j}-x \beta}{\sigma}\right)\right\}+\sum_{j \in I} w_{j} \log \left\{\Phi\left(\frac{W T P_{2 j}-x \beta}{\sigma}\right)-\Phi\left(\frac{W T P_{1 j}-x \beta}{\sigma}\right)\right.
\end{aligned}
$$

Where $\Phi()$ is the standard cumulative normal and $w_{j}$ is the weight of the jth farmer. Table 2 presents summary statistics of the WTP intervals in the NFS sample while table 3 outlines the distribution of WTP by censorship type. Of the 928 usable responses, a total of 538 zero WTP values were treated as $j \in C$. A further 4 WTP values were considered right censored at $€ 60$ while the remaining 386 were treated as interval observations. Those individuals who said they were not willing to pay anything for the conservation program and gave one of the following reasons - (1) they didn't like this bird, (2) they felt the government should pay from existing revenues, (3) the bird would be a nuisance to production, or (4) they couldn't simply afford to pay-, were considered as a point data observations of $€ 0$. Those 46 individuals who said they were not willing to pay anything 
for the conservation program and gave the reason that the price was to high were considered as interval data observations of between $€ 0$ and $€ 10$.

In our chosen model, WTP $=f$ (Size of Farm, Family Farm Income, Age of Farm Operator, Organic Nitrogen Production), REPS farm, total crops and pasture). The Organic Nitrogen Production variable is an indicator of how intensive the farming enterprise is. It is measured in kilograms per hectare and is calculated based on livestock numbers and Irish Environmental Protection Agency (EPA) Organic Nitrogen conversion factors for different livestock types. Family farm income is defined as gross farm output less total net expenses; it represents the total return to the farm labor, management and capital investment in the farm business (Connolly et al., 2007). In the model it has also been rescaled by dividing by 1000 . The size of the farm and total crops and pasture are measured in acres. The REPS farm variable is a dummy variable indicating whether or not the farmer participates in the Rural Environment Protection scheme.

\section{Results}

The parametric regression results of the value function approach (weighted using the individual farm population weights provided in the NFS) are presented in Table 3 . The Log Likelihood $\chi^{2}$ statistic shows that, taken jointly, the coefficients in the Generalized Tobit Interval model are significant at the 1\% level. As expected, the coefficient on family farm income indicates that the more profitable the farm business the more willing the farmer is to pay (significant at the $5 \%$ level) for corncrake conservation. The REPS farm variable indicates that farmer participating in the Rural Environment Protection 
scheme (REPS) are willing to pay (significant at the $10 \%$ level) higher amounts than those farmers not participating in the scheme. Given the environmental education component involved in the uptake of this scheme and the fact that farmers participating in an agri-environmental scheme are more likely to favor a biodiversity conservation program this finding was not surprising.

As expected the farms with the higher rates of organic nitrogen per hectare are willing to pay less for a corncrake conservation program. We would speculate that the main reason for this is the fact that these farms represent the more intensive enterprises that would have to make significant changes in terms of how and when they cut silage and in how they manage permanent grassland under any successful corncrake conservation program. Initially, we suspected that there may be a multicollinearity problem in the model due to potential correlation between the Organic Nitrogen Production per hectare and the REPS farm variables. However, a correlation coefficient of just -0.27 indicates very little correlation between the 2 variables. With only approximately 10000 out of 120000 farmers in Ireland exceeding the REPS limit of $170 \mathrm{~kg}$ of Organic Nitrogen per hectare (Hynes et al. 2008b) most farmers are able to comply with the scheme's limit without any changes to farm stocking rates. This, along with the fact that stocking rates vary considerably across REPS farms explains why the correlation coefficient is low.

In analyzing farmers' aggregate WTP for corncrake conservation we calculate the aggregate environmental value of the corncrake conservation program in 2 alternative ways. These are: 
1. The simple multiplication of the average value of the stated (maximum) WTP in the NFS sample by the number of farms in the country or county $\left(\sum_{i=1}^{n} \overline{W T P}_{N F S}\right)$

and

2. Aggregation using the CVM interval regression model outlined in section 4 (the value function approach) where the estimated average value of WTP in the NFS sample is multiplied by the number of farms in the country $\left(\sum_{i=1}^{n} \overline{W T}_{N F S}\right)$.

As shown in table 4, the interval based model produces average WTP values that are significantly higher (as highlighted by the $95 \%$ confidence intervals) that the average stated maximum WTP values in the sample, $€ 10.78$ versus $€ 9.07$, respectively. Given that $\overline{W T P}_{N F S}$ is the maximum the average farmer in the sample is willing to pay and $\overline{W T \hat{P}}_{N F S}$ takes into account that each farmer may be willing to pay between his maximum figure and the next value up on the payment card this is not a surprising result. Considering the fact that our modeling approach takes into account the fact that the farmer may be willing to pay more that the stated maximum amount on the payment card we believe that the value function approach is a more accurate method of estimating average and total WTP values. 
In relation to the aggregation of the WTP values it can be seen from table 4 that at the national level of aggregation, the figures are once again significantly different when

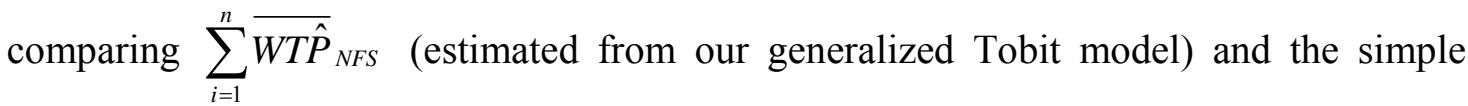
mean WTP aggregation approach for the NFS sample $\left(\sum_{i=1}^{n} \overline{W T P}_{N F S}\right)$. For the national aggregation, $\mathrm{n}$, the total number of farms is equal to 145057 (CSO, 2006). The total estimated value of corncrake conservation to the Irish farming community using our preferred valuation function approach is estimated to be $€ 1541819$. Table 5 breaks down the corresponding expenditure on Corncrake conservation in Ireland by scheme and location. Considering that the Department of Agriculture paid out $€ 20236$ to farmers under the supplementary Corncrake conservation measure in REPS in 2007 and only $€ 8403$ in 2006 and BirdWatch Ireland, under the auspice of the Irish NPWS, paid out $€ 191826$ and $€ 256127$ in their Corncrake conservation scheme in the same years respectively, it can be argued that the non-market benefits of corncrake conservation are far out weighting the cost of the conservation schemes currently in place in Ireland for this endangered bird species.

\section{Discussion and Conclusions}

In this paper we examined Irish farmers' willingness to pay (WTP) to conserve an endangered Irish farmland bird, the Corncrake. The Irish National Farm Survey (NFS) was used to produce environmental benefit WTP micro data estimates for the year 2006 using a generalized Tobit modeling approach to take account of the implied interval nature or the WTP responses in the NFS. These figures were then aggregated to get a 
total value figure for the farming community of Corncrake conservation in Ireland. Willingness to Pay on the part of farmers for conservation was also argued to be a useful guide in determining the willingness of farmers to sign up for voluntary agri-environment schemes.

There were two main findings from the analysis in terms of corncrake conservation. Firstly, it is very evident from our model results that farmers willingness to pay for the restoration of the corncrake is positively correlated with participation in existing agrienvironment schemes (in this case, the Rural Environment Protection Scheme), and with being less intensive farm operations (as indicated by our organic nitrogen production per hectare variable). We speculate that the former finding reflects the fact that REPS farmers may be more environmentally conscientious than non REPS participating farmers. Also, it may be that the less intensive farms are willing to pay more simply because they would have fewer changes to make in how their run their farm operations under any corncrake conservation programme than the more intensive farm operations.

The second main finding of the study in terms of corncrake conservation was the fact that the yearly total non-market value of corncrake conservation to the farming community in Ireland, estimated using our valuation function approach, of $€ 1541819$ was 6 times the cost of corncrake conservation programs ( $€ 264$ 530) in operation in Ireland for the reference year 2006. Considering we only looked at the WTP of farmers and not the Irish general populations WTP (and assuming the rest of the Irish population have an average positive WTP for corncrake conservation) it could be argued that the total non-market 
benefits of the program to Irish society as a whole are far greater than estimated in this paper. Furthermore, since the estimated benefit of corncrake conservation to Irish landowners are so much greater than the cost of the programs it could be argued that the conservation programs should be expanded to include farmland where the corncrake can no longer be found.

The fact that REPS farmers are willing to pay more for corncrake conservation than non REPS participating farmers may be related to the role that environmental education has to play in the REPS scheme. The local experience of farmers, the farm landscape that they work in and the farmers' depth of knowledge in relation to the wildlife on their farms may also be influencing their willingness to participate in agri-environmental schemes, their attitude towards species conservation and ultimately their WTP. Future changes to the REPS program therefore should perhaps consider the provision of specific information to farmers on how to enhance relevant bird habitats on individual farms. Training REPS farm planners in how to survey the species of breeding birds present on a farm would help in this regard and would also help farmers target their work to benefit wildlife. It is vital however that these measures are made relevant to the economic as well as the ecological realities of Irish farming.

Under current corncrake conservation programs, the Irish government's target of the reestablishment of breeding populations of the species in other parts of its former range by 2015 may be difficult to achieve. While the current conservation program should ensure the survival of the corncrake in the small pockets of Ireland where the corncrake can still 
be found, the results presented in this paper would suggest that there is considerable scope for extending out the schemes to other areas where silage is harvested as a key feed source for wintered store cattle and dairy cows on more extensive farm enterprises and which were former ranges of the corncrake. The additional cost of doing so may still be less than the total non-market benefit of corncrake conservation to the Irish farming community estimated in this paper. Without such an expansion in the scheme, the Irish government's aim of the re-establishment of breeding populations of the species in other parts of its former range by 2015 may be a very unrealistic target.

The CVM study analyzed in this paper investigated the WTP of only Irish farmers for the restoration of the corncrake into the Irish countryside. As previously mentioned, this group was initially focused on because any corncrake conservation program will only succeed if it has the support of Irish farmers, given that they manage the permanent grassland which is home to the corncrake. It would however be interesting to extend the CVM survey to the general population to calculate the aggregate WTP for the entire population of Ireland. Another limitation of the study and an area for future research relates to the fact that we did not have a geographical reference point for the farms in the NFS. The NFS is nationally representative and does not release information on the specific location of the individual farms. It would be interesting to analyze farmers willingness to pay on a county by county basis in order to examine if farmers WTP is higher in those few counties where the corncrake can be still seen (or more accurately, heard). 
Ireland faces enormous challenges in the years ahead in terms of halting the loss of the corncrake (and a number of other farm bird and animal species) from the Irish countryside. The reform of the European Common Agricultural Policy (CAP) in 2005 saw member states decoupling agricultural payments from production. The consequences of this for corncrake conservation are uncertain, but it is expected that cattle and sheep numbers on Irish farms will fall which in turn may lead to changes in mowing and grazing regimes, which ultimately may have a positive effect on the corncrake population. Apart from the loss in corncrake numbers due to changing trends in agriculture over the last 20 years, the habitats of other species of Irish bird and animal are becoming increasingly fragmented and isolated within small pockets on individual farms.

A continuation of these trends could cause further extensive biodiversity loss and according to a report by the Irish Environmental Protection Agency could lead to more than $80 \%$ loss of existing farm syrphid fauna (EPA, 2004). The results presented in this paper indicate that there is, in general, a willingness on the part of farmers to aid in the restoration of the corncrake back into the Irish countryside and also that there is a considerable economic argument for the expansion of the existing corncrake conservation schemes to areas where the corncrake is not presently found but which were part of its former range. Finally, we note that the approach followed here of estimating WTP on the part of farmers for conservation outcomes could profitably be extended to other voluntary sign-up schemes based on private land, including agri-environment schemes throughout Europe, and water quality enhancement schemes in the US and Australia. 


\section{Acknowledgement}

This paper was written as part of a Rural Stimulus Funded project, financed by The Irish Department of Agriculture, Fisheries and Food.

\section{References}

Arrow, K., Solow, R., Portney, P., Leamer, E., Radner, R., Schuman, H., 1993. Report of the NOAA Panel on contingent valuation. http://www.darrp.noaa.gov/library/pdf/cvblue.pdf

BirdLife International, 2000. Threatened Birds of the World. Lynx Edicions and BirdLife International, Barcelona, Spain and Cambridge, U.K.

BirdLife International, 2006. Crex crex. In: IUCN, 2007 IUCN Red List of Threatened Species. (www.iucnredlist.org).

Bird Watch Ireland, 2000. Birds of conservation concern in Ireland. Bird Watch Ireland Publication, Dublin

Blamey, R., Bennett, J., Morrison M., 1999. Yea-saying in contingent valuation surveys. Land Economics 75, 126-141. 
Boyle, K., Johnson, F., McCollum, D., 1997. Anchoring and adjustment in singlebounded, contingent-valuation questions. American Journal of Agricultural Economics $79,1495-1500$

Boyle, K., Johnson, F., McCollum, D., Desvousges, W., Dunford, R. and Hudson, S. 1996. Valuing public goods: Discrete versus continuous contingent-valuation responses. Land Economics 72, 381-396

Boyle, K., 2003. Contingent valuation in practice, in: Champ, P., Boyle, K., Brown, T., (Eds.), A Primer on Nonmarket Valuation. Kluwer Academic Publishers.

Carson, R., 2000. Contingent valuation: a user's guide. Environmental Science and Technology 34, 1413-1418.

Cameron, T., Huppert, D., 1989. OLS versus ML estimation of non-market resource values with payment card interval data. Journal of Environmental Economics and Management 17, 230-246.

Central Statistics Office (CSO), 2006. http://www.cso.ie/ Accessed June, 2006.

Collar, N.J., Andrew, P. 1988. Birds to Watch. The ICBP World Checklist of Threatened Birds. ICBP Technical Publication No. 8. Page Bros. (Norwich) Ltd, Norfolk, England. 
Collar, N.J., Crosby, M.J., Stattersfield, A.J., 1994. Birds to Watch 2. The World List of Threatened Birds, BirdLife International. Page Bros (Norwich) Ltd, U.K.

Connolly, L. Kinsella, A. Quinlan, G., Moran, B., 2007. National Farm Survey, 2006. Teagasc Publication, Dublin.

Copland, A., Donaghy, A., 2001. A Strategy for Corncrake Conservation in Ireland 20012010. Unpublished Report, Bird Watch Ireland, Dublin.

Department of Agriculture, Fisheries and Food, 2008a. Rural Environment Protection Scheme Facts and Figures 2006 and 2007. http://www.agriculture.gov.ie/schemes/

Department of Agriculture, Fisheries and Food, 2008b. REPS 4 - Farmers Handbook http://www.agriculture.gov.ie/schemes/REPS4/REPS4FamersHandbook_LowRes.pdf

Department of Agriculture, Food and Rural Development, 1999. Evaluation of the Rural Environment Protection Scheme. Department of Agriculture Publication, Dublin.

Daniels, R. and Rospabe, S., 2005. Estimating an Earnings Function from Coarsened Data by an Interval Censored Regression Procedure. Development Policy Research Unit Working Paper 05/91.

EPA, 2004. State of the Environment Report 2004. EPA, Wexford. 
$\begin{array}{lllll}\text { FADN, } & \text { 2005. } & \text { Concept } & \text { of }\end{array}$

http://europa.eu.int/comm/agriculture/rica/concept_en.cfm.

Green, R., Williams, G. 1994. The ecology of the corncrake Crex crex and action for its conservation in Britain and Ireland, in: Bignal, E.; Curtis, D. J. (Eds.), Nature Conservation and Pastoralism in Europe, Proceedings of the third European Forum, JNCC, Peterborough: 69-74.

Green, R., Rayment, M. 1996. Geographical variation in the abundance of the Corncrake Crex crex in Europe in relation to the intensity of agriculture. Bird Conservation International 6, 201-211.

Haab, T., McConnell, K. 2002. Valuing Environmental and Natural Resources, Cheltenham, UK: Edward Elgar.

Hynes, S., Farrelly, N., Murphy, E., O'Donoghue, C., 2008a. Modelling habitat conservation and participation in agri-environmental schemes: A spatial microsimulation approach. Ecological Economics 66, 258-269.

Hynes S., O’Donoghue, C., Murphy, E., Kinsella, A., 2008b. The Impact of REPS participation on farm chemical input usage and the production of negative externalities. Tearmann, The Irish Journal of Agri-Environmental Research 6, 16-27. 
Kleijn D., Sutherland W.J., 2003. How effective are European agri-environment schemes in conserving and promoting biodiversity? Journal of Applied Ecology 40, 947-96.

Kroeger, T., Casey, F., Haney, C., 2005. Reintroduction of the Mexican gray wolf (Canis lupus baileyi) into the Southwestern United States: An economic perspective. Paper presented at the International Wolf Conference, Colorado Springs, Colorado, 1-4 Oct. 2005. http://www.biodiversitypartners.org/econ/pub/Mwolf_paper_draft.pdf

Langford, I.H., Kontogianni, A., Skourtos, M.S., Georgiou, S., Bateman, I.J., 1998. Multivariate mixed models for open-ended contingent valuation data: willingness to pay for conservation of monk seals. Environmental and Resource Economics, 12, 443-456.

Loomis, J., White, D., 1996. Economic benefits of rare and endangered species: Summary and meta-analysis. Ecological Economics 18, 197-206.

MacMillan, D., Hanley N., Daw, M., 2004. Costs and benefits of wild goose conservation in Scotland. Biological Conservation 119, 475-485.

Martin-Lopez, B., Montes, C., Benayas, J., 2007. The non-economic motives behind the willingness to pay for biodiversity conservation. Biological Conservation 139, 67-82.

Mayes, E., Stowe, T., 1989. The status and distribution of the Corncrake in Ireland. Irish Birds 4, 1-12. 
McDevitt, A., Casey, C., 2004. The Corncrake: Crex crex in Ireland. In: Schäffer N. \& Mammen, U. (Eds), Proceedings 3rd Workshop on Corncrakes, Hilpoltstein.

Mitchell, R., Carson, R., 1989. Using Surveys to Value Public Goods: The Contingent Valuation Method. Washington, DC: Resources for the Future.

Montgomery, C., Brown Jr., G., Adams, D., 1994. The marginal cost of species preservation: The northern spotted owl, Journal of Environmental Economics and Management 26, 111-128.

National Parks and Wildlife Service (NPWS), Department of the Environment, Heritage and Local Government Ireland, 2005. All-Ireland species action plans for the Irish hare, the corncrake, the pollan and Irish lady's tresses. Downloaded at www.npws.ie.

NFS, 2003. National Farm Survey 2002, Teagasc Publication, Athenry, Galway

Schäffer, N., Green, R., 2001. The global status of the Corncrake. RSPB Conservation Review 13, 18-24.

Portney, P.R., 1994. The contingent valuation debate: Why economists should care. Journal of Economic Perspectives 8, 3-18. 
Whilde, A., 1993. Threatened Mammals, Birds, Amphibians and Fish in Ireland. HMSO, Belfast. 
Figures and Tables

Figure 1. The Remaining Breeding Ground of the Corncrake in Ireland

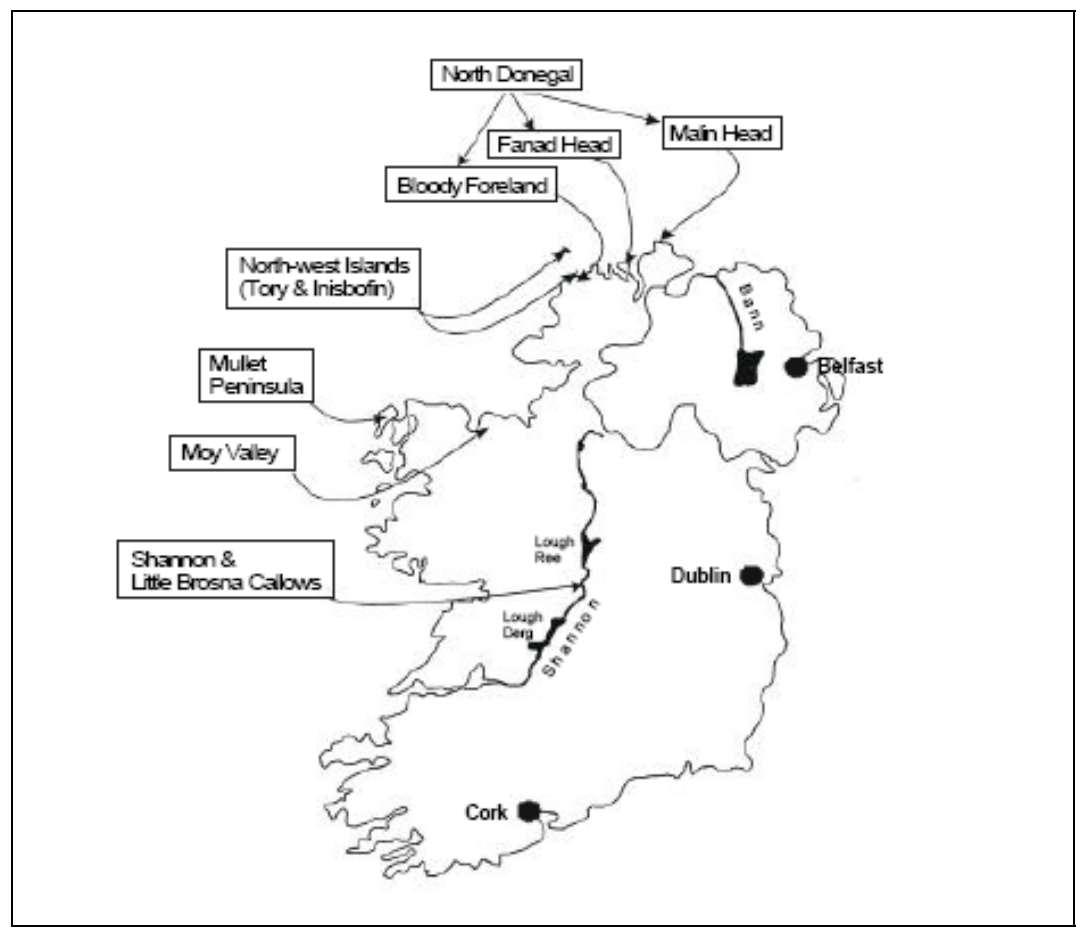

Source: McDevitt and Casey (2004)

Table 1. Summary Statistics of the NFS

\begin{tabular}{|l|cc|}
\hline & \multicolumn{2}{|c|}{ National Farm Survey Sample } \\
& 1,177 Observations \\
\hline Variable & Mean & Standard Deviation \\
\hline Size of Farm (acre) & 37.28 & 32.93 \\
Crop Pasture (acre) & 83.17 & 71.22 \\
Gross margin $(€)$ & 38980.89 & 40937.45 \\
Farm income $(€)$ & 22456.92 & 24618.09 \\
Grossoutput $(€)$ & 55465.31 & 59268.50 \\
REPS payment $(€)$ & 2386.04 & 3393.09 \\
Age (years) & 53.95 & 12.71 \\
\hline
\end{tabular}


Table 2. Summary Statistics of the WTP Intervals in NFS Sample

\begin{tabular}{lccc}
\hline Interval & Frequency & Percent & Cumulative Percent \\
\hline 0 (point value & 538 & 57.97 & 57.97 \\
$0-10$ & 46 & 4.96 & 62.93 \\
$10-20$ & 102 & 10.99 & 73.92 \\
$20-30$ & 129 & 13.9 & 87.82 \\
$30-40$ & 40 & 4.31 & 92.13 \\
$40-50$ & 20 & 2.16 & 94.29 \\
$50-60$ & 49 & 5.28 & 99.57 \\
$60+$ & 4 & 0.43 & 100 \\
Total & 928 & 100 & \\
\hline
\end{tabular}

Table 3. Interval Regression of WTP for Corncrake Conservation for NFS Sample

\begin{tabular}{lc}
\hline Variable & NFS Model \\
\hline Size of Farm (acres) & $-0.025(-0.03)$ \\
Family Farm Income $(€ / 1000)$ & $0.077(0.03)^{* *}$ \\
Age of Farm Operator & $0.05(0.05)$ \\
Organic Nitrogen Production $(\mathrm{kg} /$ hectare) & $-0.039(-0.02)^{* * *}$ \\
REPS farm^ & $2.112(1.26)^{*}$ \\
Total crops and pasture (acreage) & $-0.007(-0.02)$ \\
Constant & $10.31(-3.30)^{* * *}$ \\
Log of the estimated standard error & $2.723(-0.001)^{* * *}$ \\
\hline Log likelihood & -274362 \\
Likelihood Ratio $\chi^{2}(6)$ test & 18 \\
\hline Left Censored Observations & 0 \\
Right Censored Observations & 4 \\
Uncensored Observations & 538 \\
Interval Observations & 386 \\
\hline Robust standard error in parentheses.* significant at $10 \% ; * *$ significant at $5 \% ; * * *$ significant at $1 \%$.
\end{tabular}


Table 4. WTP estimates for the 2 alternative estimation methods

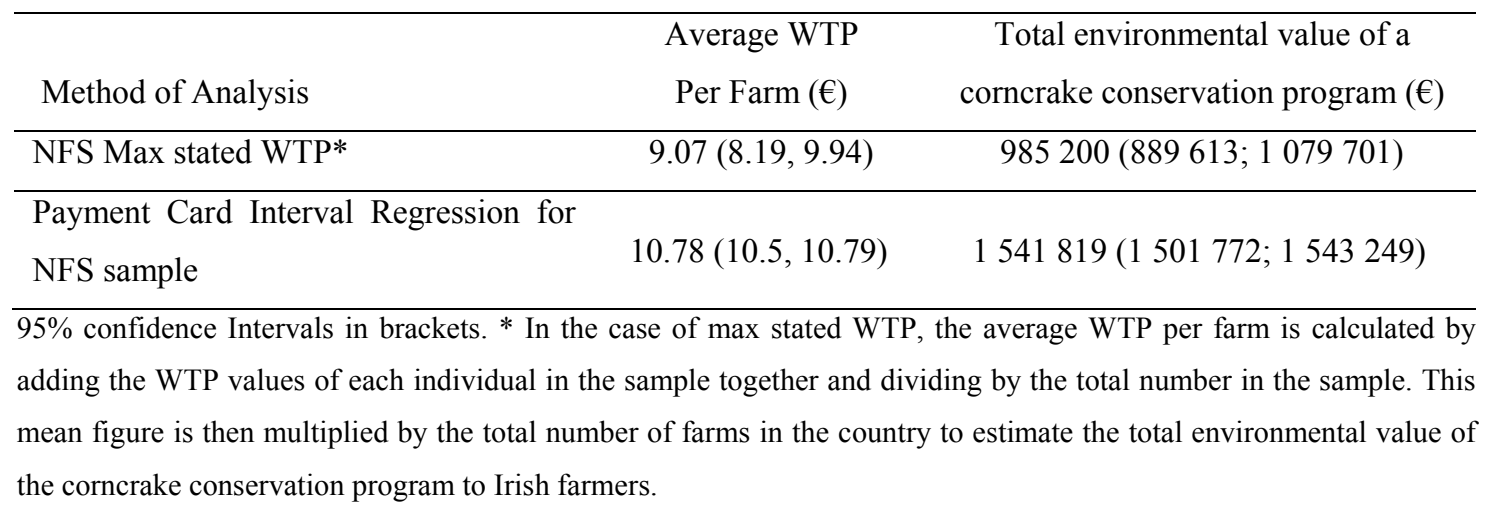

Table 5. Expenditure on Corncrake Conservation in Ireland

\begin{tabular}{|c|c|c|c|c|}
\hline Year & Conservation Scheme & Location & $\begin{array}{l}\text { Farmers } \\
\text { Participating }\end{array}$ & Expenditure \\
\hline 2006 & REPS Supplementary Measure* & Shannon Callows & 47 & $€ 8403$ \\
\hline 2007 & REPS Supplementary Measure* & Shannon Callows & 46 & $€ 20236$ \\
\hline 2006 & NPWS Corncrake Grant Scheme & Shannon Callows & 117 & $€ 117780$ \\
\hline 2007 & NPWS Corncrake Grant Scheme & Shannon Callows & 31 & $€ 24858$ \\
\hline 2006 & NPWS Corncrake Grant Scheme & Donegal & 106 & $€ 58278$ \\
\hline 2007 & NPWS Corncrake Grant Scheme & Donegal & 98 & $€ 61876$ \\
\hline 2006 & NPWS Corncrake Grant Scheme & West Connacht & 100 & $€ 80068$ \\
\hline 2007 & NPWS Corncrake Grant Scheme & West Connacht & 113 & $€ 105091$ \\
\hline
\end{tabular}

Sourse: REPS figures from Department of Agriculture, Fisheries and Food (2008b) and NPWS Corncrake Grant Scheme figures from personal contact in BirdWatch Ireland.

*REPS figures relate to numbers and payments made under the Supplementary Corncrake Measure only. 